\title{
Hybridity as Expressions of a Diasporic Community: Selected Nanyang Artists
}

Emelia Ong Ian Li, Cultural Centre, University of Malaya, Kuala Lumpur, Malaysia

emeliaong@um.edu.my

and

Izmer Ahmad, University of Sharjah, United Arab Emirates iahmad@sharjah.ac.ae

(C) 2015 University of Malaya. All rights reserved.

Malaysian Journal of Performing and Visual Arts, Volume 1, 2015

\begin{abstract}
This paper examines the paintings of selected Nanyang artists produced during the 1950s and 60s in Malaya/Malaysia to demonstrate how hybridity emerges as a way of expressing their position as a diasporic community. It proposes the concept of "play" as a way of understanding their formalistic experimentation on Chinese and Western approaches to art. However, the notion of hybridity refers to more than purely formal artistic considerations but also refers to issues of cultural identity. Their artistic considerations reflected wider concerns about home and belonging and what it means to be part of a Chinese diasporic community living in Malaya.
\end{abstract}

Keywords: Nanyang artists, hybridity, diaspora, identity, Malayan art, Southeast Asian modern art.

\section{Introduction}

This paper demonstrates how cultural identity and space are negotiated within the field of visual art through selected works of Chinese émigré artists during the 1950s to 1960s in Malaya. These artists form part of a larger group of Chinese immigrants who travelled to Southeast Asia during the early 20th ${ }^{\text {th }}$ century to settle and work. The term "Nan-yang" which means "South Seas", was commonly used to refer to Southeast Asia as the region south of China. A large number of immigrants settled in Singapore (which was part of the Straits Settlement in British Malaya), the 'centre' of Nanyang. These artists, also known as Nanyang artists ${ }^{1}$ were well-versed in both Western and Chinese artistic styles, techniques and approaches. The artists highlighted in this paper include: Cheong Soo Pieng (b.1917-1983), Chen Chong Swee (b. 1910-1985), Chen Wen Hsi (b.1906-1992), Liu Kang (b.1911-2004), Yeh Chi Wei (b.1913-1981), Tan Tee Chie (1928-2011), Chung Chen Sun (b.1935) and See Cheen Tee (b.1928-1996).

Five of them were graduates of Xinhua Art academy in Shanghai: Liu Kang (1928) Chen Chong Swee (1931), Chen Wen Hsi (1932), Cheong Soo Pieng (1936) and Yeh Chi Wei (1933). In addition, Cheong Soo Pieng attended Amoy Fine Arts Academy before going to Xinhua Art Academy, while Liu Kang and Wen Hsi attended Shanghai College of Arts. Their similarities lie in their formal art education background where Western art was taught alongside Chinese painting in Xinhua Art Academy. This was significant in that, the idea or the dilemma of responding to Western modernisation in China were by this time wellarticulated especially in Shanghai. Several main "streams" within artistic practice had emerged in Shanghai then; these included firstly, those who adapted Western concepts in art into traditional Chinese 
painting. Secondly, those who adopted Western Realism in art, particularly the styles of the Western academies of the $17^{\text {th }}$ and $18^{\text {th }}$ century. Thirdly, those who adopted European modernist art which includes Impressionism, Expressionism, Cubism, Fauvism, Symbolism and Post-Impressionism.

The artists mentioned above migrated to Malaya at different times: Chen Chong Swee in 1931, and Cheong Soo Pieng in 1946 and Chen Wen Hsi in 1948. Yeh Chi Wei migrated to Sarawak in 1919, went back to Fuzhou, China in 1925 and then returned to Malaya in 1937. Liu Kang moved to Muar in 1926, went to Shanghai from 1926-37, stayed in Muar 1937-42 and then lived in Singapore from 1945 onwards. The other three artists graduated from the Nanyang Academy of Fine Art in Singapore during the fifties: Tan Tee Chie in 1951, See Cheen Tee in 1953 and Chung Chen Sun in 1955. Tan Tee Chie came to Malaya age 11 during the Sino-Japanese war. Chung Chen Sun, who later established the Malaysian Institute of Art, was born in Malacca while See Cheen Tee was born in Terengganu. This latter group of artists has been generally referred to in local art historical writing as the second generation of artists (Piyadasa 1979; Chung 2004). They were considerably influenced by the first generation of artists who came from China in terms of drawing from both Chinese and Western painting traditions in their work but subsequently developed their own diverse artistic styles.

The paintings of these Nanyang artists exist as interesting examples of how their artistic explorations were worked out against a particular historical juncture that defines their identity as a 'diaspora' community during the pre and post-independent period in Malaya ${ }^{2}$. The notion of hybridity is employed here to examine their formalistic explorations, which may be viewed as expressions of a diasporic community.

This paper employs approaches of the new art history ${ }^{3}$ which encompasses formal analyses of artworks, supplemented by contextual analysis gathered through archival research, interviews with artists, art historians, curators and various secondary resources. The notion of hybridity and diaspora is privileged in this paper to highlight the fact that these different artistic solutions are not just purely formal artistic considerations but are also strategic decisions, based on issues of cultural identity. Their artworks reflect their wider concerns about home and belonging as a Chinese diasporic community living in Malaya.

Further, by locating their artworks within the discourse of hybridity and diaspora, the negotiation of cultural identity may be viewed as a form of "play" between cultures - a to-and-fro exchange that is based on an equality of the contrasting positions, and marked by an acceptance of the otherness of the other. The choice between Chinese or Western ways of seeing within the field of visual art may be related to larger questions about how non-Western identities are different from or the same as Western identities. Therefore, hybridity also emerges as an expression of the artists' social reality. It is a coping strategy, a way of making sense of their lives in Malaya and of negotiating cultural difference. In these examples, different languages of art were intentionally adopted and employed as a way of expressing hyphenated identities.

This paper also regards identity, in particular Chinese identity, as a discursive and constructed notion. Since the maintenance of identities depends on "symbolic resources" (Hall 1996: 2) located within cultural practices, art as cultural production may be viewed as a "signifying practice" that maintains such identities. Hence identity is a verb, an act, meaning that it is constituted through praxis. Identity is always "under construction", a transforming entity rather than something inherent or fixed that can be recovered. Artistic works are cultural productions that enable the visual description and re-description of a particular "way of life" and have the power to indirectly reiterate certain values associated with a community. In other words, it has the power to both reinforce as well as dismantle essentialist concepts of identity.

This paper suggests that artistic practices of these Nanyang artists cannot be fully understood when explained merely via "China's response to the West" or Western modernisation (See Sullivan 1959). Although it is acknowledged that these are the political and cultural contexts from which the artworks emerged, and remain relevant to the analysis, it does not account for the differences between the works 
produced in Malaya and in China. Additionally, the incorporation of Southeast Asian "essences" and subject matter is used to explain this difference. But here again, the adoption of "Nanyang" subject matter, does not fully explain the multifaceted character of their artworks. Hence we employ the notion of hybridity and diaspora, in an effort to link their diverse artistic directions to the expression of their heterogeneous identities and the struggle to work out their diasporic concerns.

\section{The notion of hybridity}

Within postcolonial studies, hybridity has been used as a cultural-political concept to challenge such polarities as the (dominant) West and the (subordinate) Other. It has also been a key concept within cultural appropriation and conceptualizations of cultural borders. Writers such as Pieterse (2001), Papastergiadis (2005) and Ang (2001) maintain that it is possible to avoid taking up extreme positions on the concept of hybridity if we rely on alternative theoretical frameworks that focus on how communities react to cultural differences or discrimination. Hybridity is employed in the latter to examine the boundaries of essentialised identities. Since it is through cultural codes that these boundaries are marked out and maintained, cultural productions, such as art in this case, serve as dynamic sites for the negotiation of identity.

It should be noted however, that the notion of hybridity within the artistic practices of these Nanyang artists should not be celebrated in a post-modernist sense (as a "celebration of flux and indeterminacy as the product of the mobility of global capital") because this perspective ignores the inequalities of access to socio-political or economic power. (See Coombes 1998). We suggest that the heterogeneous Chinese artistic community in pre-independent Malaya occupies different spaces between two somewhat extreme positions of post-modernist (or metropolitan) hybridity and postcolonial hybridity ${ }^{4}$. The complexity of their diasporic position emerges in their dual belonging to the cultural spaces of Malaya and China. As much as their claims of belonging as a diasporic community in Malaya required validation, they were also able to depend on a "stable" Chinese identity from which different positionalities were adopted.

Their diasporic identity is characterised firstly by "forced dispersion" from the homeland, as the first generation of artists were part of the larger exodus of Chinese immigrants during the Sino-Japanese war (1937-45). They came to Malaya in search for employment and a better life, not knowing if they would return. Yeh Chi Wei, for instance, said: "I originally intended to stay only for two or three years before returning to China. Who would have known that I would stay on and live here for the past 32 years" (Yeh 2010:59).

Secondly, this diasporic identity is also characterised by "homeland orientation" described by Brubaker as the different ways a community continues to maintain cultural connections to their homeland either directly or vicariously, in ways that affect their identity (2005). For instance, Chung Chen Sun and See Cheen Tee were born in Malaya but their practice or knowledge of Chinese traditional painting maintained their cultural connections to China. Thus, the diaspora perspective purposefully underscores the different relationships the artists continued to have with their "home country" while being in Malaya.

Many of their artistic decisions were grounded upon issues of belonging to a new culture, in this case a Malayan culture, located within the larger regional culture of "Nanyang" or the South Seas (Southeast Asia). The artistic community as a diaspora is an alternative Chinese identity that developed out of this creative tension of belonging to both cultural spaces. This does not mean that "alternative" Chinese identities simply emerged naturally as a result of day-to-day contact with other cultures in Malaya. These artists were constantly reminded that "they do not live in China anymore" (Y. K. Lim, personal interview, Jul 13, 2012). These artists had to rethink their positions as immigrants "who now live in Nanyang and must paint as people who live here" (Y. K. Lim, personal interview, Jul 13, 2012). The realisation that they no longer live in China compelled them to gaze back to their homeland out of a sense of nostalgia and necessity. 
In "The voice of the motherland" (2011) Liu Kang's note on introducing the "quintessence of the art of our motherland" to "Nanyang" seems to suggest that the art of the motherland can be summoned as an antidote to the feeling of alienation in one's new locale. Thus, the position of belonging is one that is created from without, i.e., by the external factor of dislocation rather than one that naturally emerges from within. This again reinforces the idea of identity as conscious and intentional creation rather than natural and essential. His experience exemplified the characteristic of a "South Asian diaspora [who are] not so much oriented to roots in a specific place and a desire for return as around an ability to recreate a culture in diverse locations" (Clifford 1994: 302). In the same way, we suggest that Liu Kang and the other artists discussed here, were focused on "recreating a culture" as a way to belong to Malaya. However, they did not attempt to merely reproduce the culture of their homeland, rather they reformulated this culture to accommodate their need to belong as well as validated their claims of belonging. This reconstruction of culture took the form of hybrid artistic experimentation.

\section{Hybridity and the notion of play}

These diasporic artists were in many ways bound by the expectations to fuse Western and Chinese artistic traditions. It may be argued that as a diaspora community in Nanyang, these artists were freed from the roles they had to play in mainland China, thus Malaya provided for them that "neutral" ground on which the Chinese and Western ways of seeing could be adopted or discarded at liberty. However, we need to qualify that the word neutral here does not mean that the political inequalities in power are suddenly made irrelevant or simply forgotten. But, it may be suggested that being in the diaspora allowed the artists a temporary suspension of national/political ties to either Malaya or China.

Ien Ang argues that the "metropolitan space of the global city" is the place where such hybrid practices and cultural exchanges take place, "more than the nation-state as a whole" (2001: 89). She quotes Appadurai that metropolitan cities are "spaces with a sense of place and identity which is "substantially divorced from their national contexts" (89). Singapore in the 1950s and 60s, could be considered a metropolitan city, (besides Kuala Lumpur and Penang) an artistic and cultural centre where art exhibitions were held and where the Nanyang Academy of Fine Art (NAFA) was located. The said artists were all either educated at the NAFA or lived in Singapore. This vibrant environment provided them impetus for artistic experimentation. Cheong Soo Pieng for instance, was able to resign from his job as a teacher in 1961 and practice art on a full-time basis. This signalled a sufficient infrastructure and supportive art market for a professional practice.

This differs from mainland China where negotiations, centred on accepting or rejecting "foreign elements", were linked directly to China's survival as a modern nation. Artists were inclined to resist or assimilate artistic approaches in ways that define difference. Such artistic exchanges could not be separated from their nationalistic context (Kao 1998; Croizier 1993). In contrast, the artworks produced by the diasporic artists in Malaya demonstrate an unhurried and consistent exploration of form in contrast to the urgent need to either adopt, reject or reconcile Eastern and Western approaches. We suggest that this was somehow made possible by the fact that they were a diasporic community.

Paul Armstrong, in his essay on "Play and Cultural Differences" postulates play as "acts of representations" which "stages interactions between values, conventions and ways of seeing which otherwise might not encounter each other" (2001: 65). He emphasized that, “... these acts of staging are not necessarily a resolution of differences but a playful, inconclusive, back-and-forth movement" (65). Similarly, this paper leverages "play" where one culture may say something about another culture without "engaging in a hostile act of appropriation" which "makes possible a non-coercive, non-reductive appreciation of otherness" (71). Subsequently, play allows for differences to exist and engage in dialogue without fear of subjugation. It will be demonstrated in the following works that these artists held this open, non-coercive attitude towards art. The cultural encounter between East and West, often antagonistic and characterised by the need to dominate, is overshadowed here by other diasporic concerns. This enabled the artists to view Western approaches not as better than or inferior to Far Eastern approaches. 
Tan Tee Chie who taught Chinese ink painting in NAFA says, "There are no conflicts. Western art techniques provide one approach. Traditional Chinese painting points to another way. An artist can choose whichever techniques that can best portray the subject matter (T. C. Tan, personal interview, Mar. 24, 2004).

Along similar lines, Chung Chen Sun remarked that, "Western artists pursues realism and abstraction to both extremes in order that they may seek truth in art, but the Chinese artists tries to find a balance between the two, because tao can only be achieved through a balance (C. S. Chung, personal interview, Aug 6, 2006). Both similarities and difference are acknowledged in play. The aim is not to remove difference or to insist on underlying similarity but to engage in a game of reciprocity.

Yeh Chi Wei, in his attempt to encourage students to observe nature as a necessary requirement to painting, quoted both Chinese traditional sources and Western sources:

Consider also Shi Tao, who lived from the late Ming Dynasty to the Qing. ...Had he not feasted his eyes on picturesque scenes from nature, he would not have been able to make his brilliant contributions to the history of Chinese landscape paintings. In addition, we are reminded of two great Dutch landscapists of the 17th century - i.e., Allart Van Everdingen (1621-1675) and Jacob Isaacksz van Ruisdael (1629-1682). For the sake of further enlivening and beautifying their pictures, they went as far as the fields of Sweden and Norway to study the mountains and waterfalls. (Yeh 2010: 32-33)

The reconciliation of the two traditions becomes irrelevant. What is highlighted here is the ease with which different ways of seeing may be adopted and discarded. The artists did not choose to resolve differences between the ways of seeing, they acknowledged it and their range of artworks demonstrates that they did not have a problem producing an artwork that would totally fit into the category of "Chinese traditional painting" or fit perfectly into a "Cubist" mould. It could be argued that formalistically at least, one could not tell if some of it were Cubist artworks produced in Paris, had the biographic details been withheld. Thus, their artworks serve as uncommon products or outcomes of "play" where the equality of contrasting positions is marked by an acceptance of the otherness of the other. This also demonstrates that when play is allowed to happen, cultural encounters are productive, and new possibilities and ways of seeing emerge.

Having said that, relating the artists' work to hybridity and the notion of play does not directly translate into acceptance between cultures in a real sense. It does not easily remove cultural prejudices and nor does it even out the playing field. As Garcia Canclini pointed out, "hybridisation is not synonymous with reconciliation among ethnicities and nations, nor does it guarantee democratic interactions" (2000: 48). It may, however work together with other strategies to open possible paths for living with difference without animosity. Below are some examples of how the process of play produced innovative pictorial solutions (see Figures 1-4).

Yeh Chi Wei, who headed the Ten Men Group in 1961 is well-known for actively organising sketching trips throughout the region. This included the Malayan East Coast (1961), Java and Bali (1962), Thailand and Cambodia (1963), Sarawak (1965), Sabah, Brunei, Miri (1968) and Medan, Berastagi, Lake Toba in Sumatra (1970) (Yeh 2010). Through his close observation of local subject matter, Yeh experimented with methods of applying Western oil paint to achieve his unique artistic vision. Portrait of a Dayak Lady shows a head of a lady that is hemmed in by two flat, densely painted areas (see Figure 1). The thick gold decorative motif above and the white foreground act as protective enclosures that do not allow the viewer to impose on the figure. Rather than just providing a rustic allure, they distance the subject from the viewer and delineate the subject matter as belonging in the past. He has developed a method using oils which produced an effect akin to ancient Chinese Han ink rubbings which he views as a method which most aptly expresses this subject matter. This turn to archaic sources is not so much a return to his own cultural roots but more as a way to lend a timeless quality to the paintings. He said, "whatever the case may be, painting is like a universal language that crosses national, racial and geographical 
boundaries" (2010: 14-21). Yeh's pictorial language that places the natives of Malaya and Borneo as cultures of antiquity by way of a Chinese art form demonstrated his identification with them.

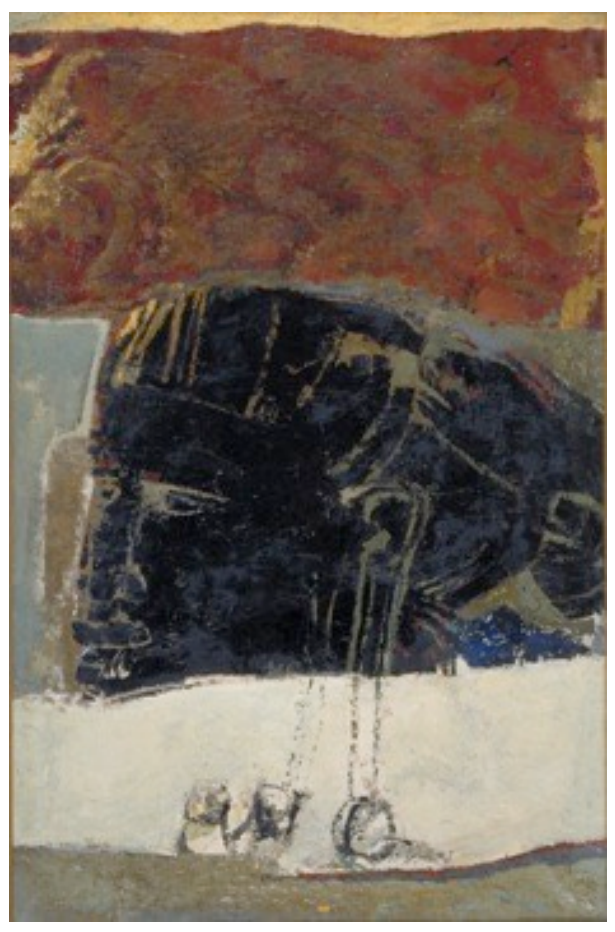

Figure 1. Yeh Chi Wei, Portrait of a Dayak Lady, Oil, 95 x 62 cm, 1969, Collection of National Heritage Board, Singapore. Photo: National Heritage Board, Singapore.

Chen Wen Hsi, whose works range from representative modes to total abstraction, has been influential on many second generation Nanyang artists in terms of his approach to abstraction. In Abstract Cranes, Chen Wen Hsi employed a Western compositional format coupled with the use of Western medium of oil and its approach to colour and form (see Figure 2). The shapes created emphasize flatness and there is no hint of the brushstroke, its forms being clearly delineated. Wen Hsi seemed to have reconstructed the forms so that they do not at all represent the physical form of the crane. In this way, it reminds us of the fragmented forms of Synthetic Cubism ${ }^{5}$ which is not only a process of "breaking down" forms but also a process of "building up" forms. However, we suggest that the use of space seems to rely on a method in Chinese traditional painting where forms are related to one another through the rhythmic voids or empty spaces in between dominant figures. Rather than being anchored down by gravitational force or pulled towards a central point, the forms just float weightlessly. The flatness of the picture plane is also contrasted with smaller forms in lighter colours which gives the painting a "foreground" and "background".

Wen Hsi said of his experimentation with abstraction:

900 years earlier in China, the great poet-artist Su Dongpo advocated that, "paintings which emphasize the likeness of form can only be compared to children's works; poetry which shows no originality does not come from the hand of a true poet." [...] I believe this is the earliest concept of abstract art in the Far East" (2006: 66).

In this way, Wen Hsi often stressed that a painter should not be limited by physical appearances. Subsequently, as his works demonstrate, he recognised the parallels to this principle within the modernist art movements of Post-Impressionism and Cubism. While Wen Hsi adopted different elements from 
Western art to suit his artistic purposes he also implied that the vital differences between the two artistic sources need not be reconciliated. He said:

Western art has a particularly strong influence on my Chinese paintings in terms of composition and layout. Breaking away from established conventions on layout [in Chinese painting], I paid special attention instead to Western theories on compositional format, studying their aesthetic principles of harmony, contrast, symmetry, rhythm, balance and so on. (2006: 66)

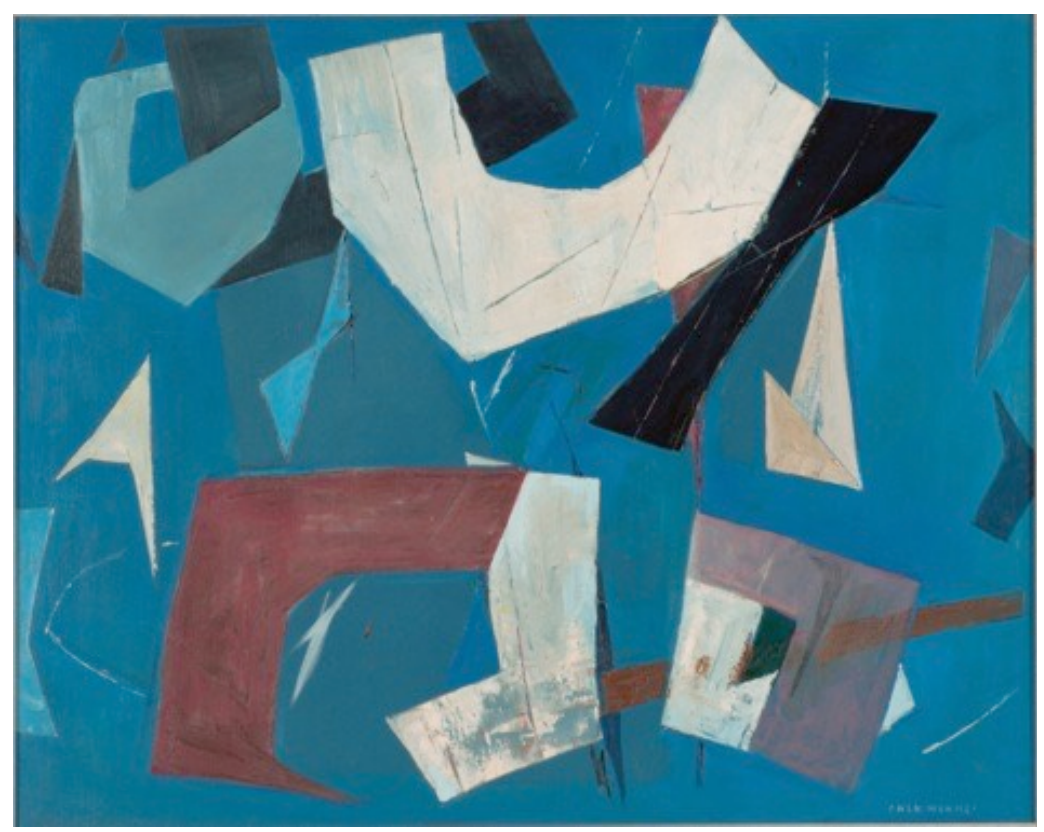

Figure 2. Chen Wen Hsi, Abstract Cranes, 1960s, oil on canvas, 110 x $100 \mathrm{~cm}$, Collection of National Heritage Board, Singapore. Photo: National Heritage Board, Singapore.

Chen Chong Swee, who broke new ground in Chinese traditional painting in Malaya, encouraged fellow painters working within the Chinese painting tradition to depict actual sceneries in their daily life and incorporate Western techniques and new subject matters (Kwok 1993). He wrote for the Society of Chinese Artist (1948) that:

[...] instead of the Westernisation of Chinese art, it would be more fruitful to view the development in Western art since Impressionism as reaching towards the aesthetic ideals of the traditional Chinese ink painting. This process is seen in the Western painting's increasing emphasis on the subjective in artistic intentionality, linearity in pictorial expression and the preference for extra-worldly subject matters... (p. 9)

His emphasis on the similarities between the two traditions is a way of negotiating the otherness of the West. Chen Chong Swee was a pioneer in educating art students how to approach the two artistic traditions. In Pounding Rice, he uses a compositional method derived from Chinese traditional painting ${ }^{6}$ (see Figure 3). Here, the use of a horizontal scroll format encourages a horizontal reading of the composition. Depth is suggested, not by a continuous receding ground plane (more common to western naturalistic representation of 3-dimensional depth), but by subtle spacing between the figures and its 
decrease in size. However, this compositional method is combined with the use of a balancing centre ${ }^{7}$ provided by the rice pounder which establishes a stabilizing centre on which the eye is brought back to the middle. The informal (as contrasted to a symbolic or didactic orientation in Chinese traditional painting) character of the painting is accentuated by the casual conversation of the women in the foreground and the passing of the women at the back. The heads of the figures also seem to be larger in size which is a practice in Chinese traditional painting where the size of an object or figure is determined by its significance as a subject in the painting rather than its actual physical size. Chen also introduced Western naturalism in this painting by employing subtle light and shade as well as naturalistic colour.

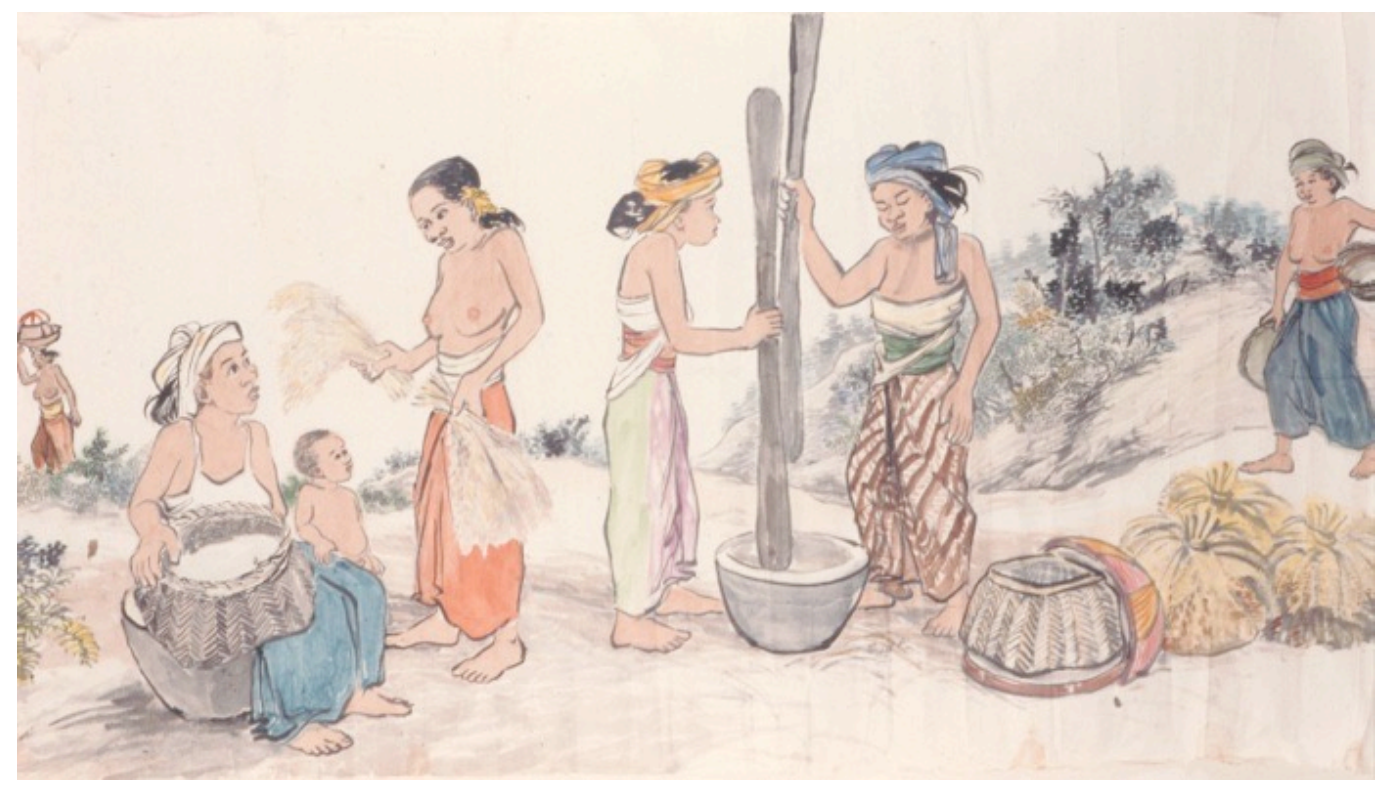

Figure 3. Chen Chong Swee, Pounding Rice, undated, Chinese ink and colour, 117 x $242 \mathrm{~cm}$. Collection of National Heritage Board, Singapore. Photo: National Heritage Board, Singapore

Chung Chen Sun, who was a student of both Chen Chong Swee and Chen Wen Hsi, has also been recognised for innovative techniques in Chinese ink painting. He reiterates that while outwardly, his work may employ Chinese ink and brush techniques, it is not typical of Chinese traditional ink painting in China (C. S. Chung, personal interview, Aug 6, 2004). This is because the incorporation of Malayan subject matter and Malayan living itself transforms the composition, the technique and the focus of the painting. Furthermore, his paintings are always informed by his knowledge of Western media and approaches. (C. S. Chung, personal interview, Aug 6, 2004). The Fishing Village marks the beginning of his experimentation with Western abstraction and the compositional format of the Chinese hanging scroll (see Figure 4). This exploration became more fully developed during the 1980 s as evidenced in artworks like Durian Seller (See Chung 2004: 180). 


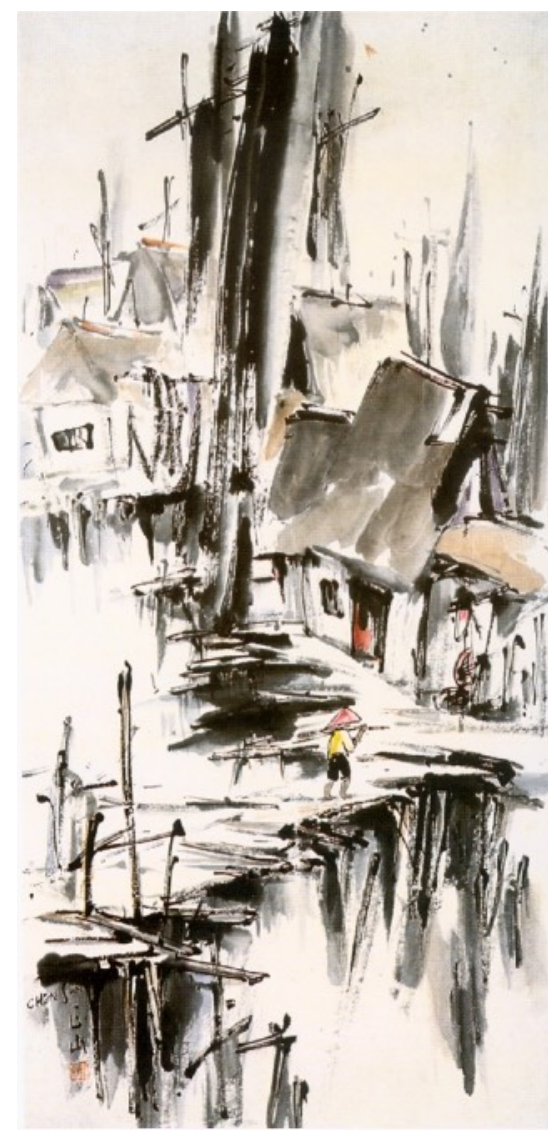

Figure 4. Chung Chen Sun, Fishing Village. 96 x $46 \mathrm{~cm}, 1965$, Collection: National Art Gallery. Photo: Author.

Cheong Soo Pieng is one of the four artists who went for the Bali trip ${ }^{8}$ in 1952. Upon returning from the trip, Cheong Soo Pieng's work have been well-known because of its influence to second generation Nanyang artists and its role in the development of the "Nanyang style" and the emergence of the figuretypes $^{9}$ (see figure5). Evidence suggest that Soo Pieng's figure-types may have developed out of his explorative play between Western Cubist styles and Southeast Asian craft and woodcarving traditions. Claire Holt, for instance, pointed to Balinese wood sculptures and the tjili ${ }^{10}$ for the emergence of elongated limbs in some of the artworks of both Balinese and European painters. Seng and Tng (2010) pointed out that Soo Pieng's early sketches produced in 1950 depicted shadow puppets with elongated limbs. While Piyadasa suggested that Soo Pieng drew inspiration from the hampatong ${ }^{11}$ sculptures. Additionally, Lim Hock Ann stated that his father, Lim Cheng Hoe, a close friend of Soo Pieng, had mentioned that Soo Pieng was fascinated with Picasso's Rose period and it was these works that inspired his subsequent paintings on stylised figures (H. A. Lim 2010). All these suggestions propose the probability that his "figure-type" was a culmination or play of different artistic traditions and cannot be attributed to a singular artistic resource. We reiterate that Soo Pieng's artistic process thus exemplifies the notion of play where the artists may adopt or disregard different elements from different artistic resources as a vital part of the process of artistic experimentation. Authenticity of forms or reconciliation of artistic traditions are thus irrelevant. 


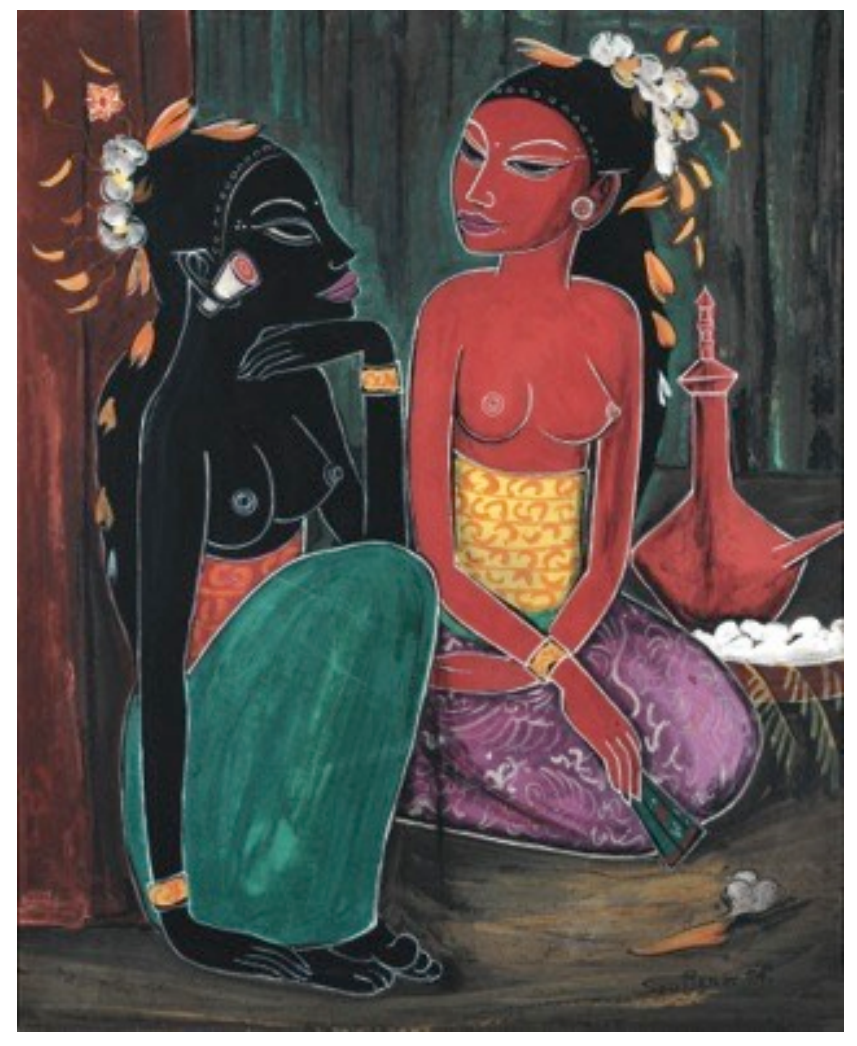

Figure 5. Cheong Soo Pieng, Balinese Maidens, 1954, Gouache on board, 75 x $60 \mathrm{~cm}$, Collection of Ong Yew Huat. Photo: Ong Yew Huat

In conclusion, we recapitulate that by locating their artworks within the discourse of diaspora, we can see how hybridity here emerges as a form of "play" - a to-and-fro exchange between cultures that acknowledges both similarities and difference without hostility. In many instances, the differences are allowed to exist side by side, similarities overlap and relate to each other, just as ambiguities are left unresolved.

However, as mentioned, hybridity also emerges here as an expression of the social reality of a diasporic community. Therefore, while the artists maintained links to their homeland through artistic practice, they also began to establish links to their "new homeland" within the same diasporic space. The next section of this paper will thus illustrate how they negotiated this new Malayan identity and positioned themselves strategically within the national narrative.

\section{Negotiating a Malayan identity}

As a diasporic community, their role in the production of a new Malayan identity has potentially significant political implications in Malaya. Their artistic decisions may be viewed as politicised and carefully crafted articulations about questions on belonging and representation in the context of the nation-state. It may be suggested that these artists consciously identified themselves as artists of Nanyang to gain political agency and looked for ways to represent themselves by choosing subject matter that were emblematic of the South Seas and its way of life. 
As some writers have pointed out, approaching the artworks within the context of diaspora ultimately provides us alternative readings that can be contrasted with the official national narratives. This is because "diaspora questions the language of integration, assimilation or inclusion assumed within national frames" (Ahmed 2003: 8). Nationalism requires a certain degree of cultural uniformity and the construction of a homogenous public culture and identity. In this sense, diaspora challenges the notion that territorial connections or cultural relationships should be taken for granted as "natural sources of identification" (Kalra 2001: 32). Diaspora contests the static conceptualization of a nation as one with distinct physical or cultural boundaries.

The artistic approaches and practices of these diasporic artists may be seen to work in two contradictory ways. Firstly, it is an identity that is continually changing to position itself positively and productively within the national narrative. As such, the choice of subject matter, consistently based on the "Nanyang" demonstrates this desire. Secondly, their preoccupations with artistic discourses that began in Shanghai, and their attempts to explicate their "Chinese" identity, continue to remind us of their enduring relationships with their homeland. Thus, within the same diasporic space, transnational and national ties are established.

The artists' incorporation of Nanyang subject matter adds an interesting dimension within the diaspora context. It may be argued that their response to "paint as people who live in Nanyang" by choosing subject matter derived from "place" seem to depend on a nativist idea of a nation. However, their concept of "place" was based on a selective yet loosely demarcated space which included besides Malaya and Borneo, places like Bali and Java. During the well-publicised 1952 Bali sketching trip, the idea of a Malaysian or Singaporean nation-state had not yet emerged. The artists were thus thinking of a distinct region which was then known primarily as the South Seas or Nanyang in terms of geographic as well as cultural terms. Although some writers have problematised this distinction of the region on both counts, it is beyond the scope of this paper to discuss whether the South Seas is a culturally distinct region. What is significant is that from the artists' viewpoint, what they termed as "Nanyang" included various parts of modern Southeast Asia. The term Nanyang is also used loosely — at times to mean Malaya, and at other times to mean Southeast Asia.

The artists did not seem to consider the cultural or artistic centre of Nanyang as being in Singapore or Malaya, even though most of them were then residing in these two places. Instead, they attempted to locate "authentic" Nanyang cultures within the primitive or older cultures of Nanyang. They found this in the island of Bali. Liu Kang for instance quotes Charlie Chaplin who said, "Those who have not been to Bali cannot be considered as having been to Nanyang" (2011: 57). Some of their ideas on Malayan identity seem to rely on an essentialist concept of the native as simple, hardworking and innocent. ${ }^{12}$

It may be suggested that the diasporic artists' expression of a Malayan identity (based on such essentialist qualities), pose several problems to the idea of a homogenous nation that has distinct cultural practices or cultural history. Firstly, they went beyond the borders of Malaya to depict Balinese cultures and other Nanyang cultures. This challenges the notion that the cultural borders of Malaya can be markedly drawn. Rather it interprets the space of Nanyang as the larger space of Southeast Asia and underscores the arbitrary demarcation of Peninsular Malaya and Singapore. Secondly the expression of an essentialist Malayan identity based on subject matter was their way of relating their work back to the Nanyang and served to justify their belonging to Malaya.

See Cheen Tee's Three Generations illustrated an image of the women in a family sitting together. This is not a depiction of family life in a casual setting, but a highly stylised composition with each figure carefully positioned on a piece of Malay woven mat (see Figure 6). Even though the mother is depicted in a Chinese samfu and the baby is wearing red, a colour often symbolically tied to China, the older generation - the grandmother is depicted wearing a kebaya and a malay sarong. Through this symbolic arrangement of the mat and use of attire as a cultural marker, this image implies that there is a shared cultural or historical lineage between the Chinese and the local communities of Nanyang. 


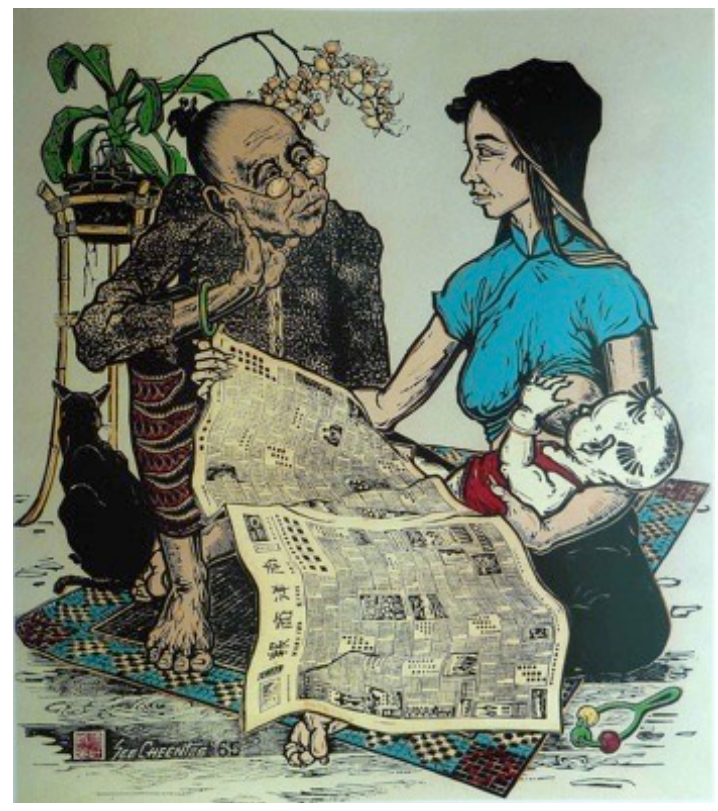

Figure 6. See Cheen Tee, Three Generations, 1965, Woodblock Print. $62 \times 49 \mathrm{~cm}$, Collection of See Yee Wah. Photo: See Yee Wah.

Daily rituals of life at the kampung or the fishing village were a recurrent theme and subject matter in many works (see Figure 7). Attap houses, ubiquitous in Southeast Asian vernacular architecture were frequently featured (see Figure 4 above). The artists also depicted the socializing of the three major ethnic groups, the Malay, Chinese and Indian communities. They are usually differentiated by their attire, their distinctive facial characteristics and portrayed within an unhurried, carefree environment. Similarly, the theme of leisurely kampong life is carried through in Liu Kang"s Painting Kampung. In this example, the gathering of the kampong folk around a Chinese artist expressed in naiveté tone of flat shapes and colours reflect the unfettered living in the kampung. The naive treatment of colour and form reflect the innocence of village life where differences in ethnicity are less affected by the politics of identity.

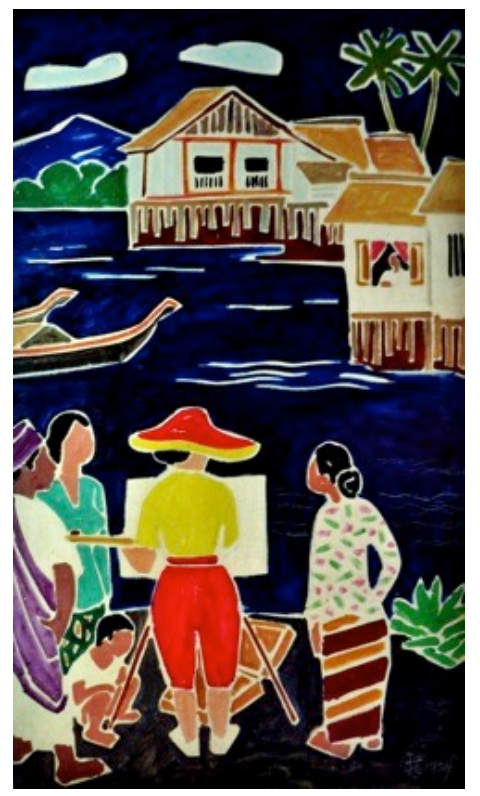

Figure 7. Liu Kang, Painting Kampung, 1954, Oil on canvas, $120.5 \times 71 \mathrm{~cm}$, Collection of National Heritage Board, Singapore. Photo: National Heritage Board, Singapore 
Brobak Birds Competition, is yet another example of the deliberate selection and inclusion of "Nanyang" or local subject matter. In this woodblock print, Tan Tee Chie takes pains to carefully depict the multiethnic local community coming together for a local bird-singing competition. The inclusion of the date on the trophy (bottom right corner) relates that it is an actual event. It illustrates how local forms of leisure can be equally appreciated by bird enthusiasts who come from different cultural backgrounds (see Figure 8).

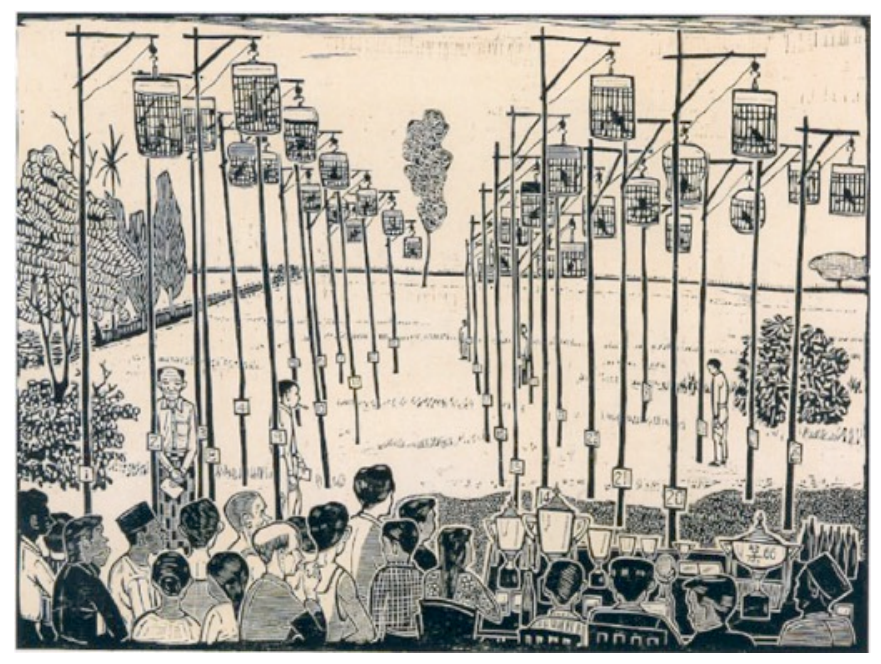

We argue that such depictions should not be dismissed as mere romanticisation of Malayan life. It should be noted that these paintings were produced during an uncertain period in Malayan history where various socio-political developments had increased communal tensions between the communities. Against this backdrop, their works may be viewed as a conciliatory effort to gain the acceptance of the native communities of Malaya. Additionally, some of these artists spent their childhood in the rural countryside where being close to nature was a joy, a hardship and an experience embedded powerfully in memory. Cheong Soo Pieng, for instance, came from a family who worked in agriculture and fishing (Seng 2010). See Cheen Tee grew up in the coastal town of Terengganu where his family reared pigs and poultry, went hunting in the jungle and tapped rubber for a living (Chia 2001). Chung Chen Sun recalled living near padi fields where the water buffalo and the cockerel were an everyday sight (Chung 2004). Thus, many of these subject matter were based on such actual experiences rather than an imagined experience based on a longing for the idyllic.

\section{Conclusion}

It is hoped that the artistic practices of these artists will offer another example that demonstrates how as a diasporic community, the Nanyang artists were shaped by contexts particular to the Malayan experience. Their artistic experimentation as understood through the notion of play in particular, is an example of how their practices may be differentiated from those in mainland China and also serve as interesting examples of how hybridity can go beyond essentialist identities and express the "complicated entanglements" of a diasporic community.

The recognition of the plural nature of diasporic communities only remind us that we should not overlook the specificity of individual experiences. Aside from examining the artworks collectively and ascertaining common themes, we need to acknowledge that although they share an outwardly similar educational background and diasporic experience in Malaya, they travelled through different paths and arrived at different conclusions. This emphasizes the specificity of diverse experiences that make up such hybrid productions. As a whole, the artworks they produced give us a sense of that complex and varied hybrid experience. 


\section{Endnotes}

${ }^{1}$ The term Nanyang artists has been employed loosely in local art writing to refer to Chinese émigré artists who taught or studied at the Nanyang Academy of Fine Art, it also includes artists who were closely affiliated to them and subsequently local-born artists who studied there. The term will be employed throughout this paper to refer to this selected group of artists.

${ }^{2}$ Throughout this paper, the term Malaya refers to both Peninsular Malaysia and Singapore.

3 Jonathan Harris points to the 1970s as the beginning of a radical development in art history, which changed the latter's approaches, methods, theories and objects of study (2001). He linked these developments to broader theoretical and intellectual developments in various fields outside of art history, particularly in Marxist, feminist, psychoanalytic, semiotic, structuralist and postcolonial theories. These new approaches to art history de-emphasized formalistic analysis and underscored contextual analysis, fed through these new theoretical frameworks. They were subsequently known as the "new art history", "radical art history" or "critical art history."

${ }^{4}$ See R. Radhakrishnan's differentiation of 'metropolitan hybridity' and 'postcolonial hybridity' in, 'Postcoloniality and the Boundaries of Identity.' Callaloo 16: 750-771 (1993), p 753.

5 Synthetic Cubism, a term coined by Alfred Barr, was differentiated from Analytic Cubism in that the forms were constructed or assembled rather than broken down in parts.

${ }^{6}$ Art historian T. K. Sabapathy described the composition of the horizontal or vertical scroll format as such, 'a Chinese painting does not assume a fixed position of spectator rooted to one spot outside the painting. The total spatial construction depends on the moving focus of the viewer within the scene,' in T. K. Sabapathy, 1986, p. 134.

${ }^{7}$ A balancing center, as a stable base of composition where the eye comes to rest, is a common compositional method in western paintings. See Arnheim, 1988, p 109.

${ }^{8}$ The other three artists who participated in this sketching trip include Chen Wen Hsi, Chen Chong Swee and Liu Kang.

${ }^{9}$ A term introduced by art historian T. K. Sabapathy to refer to Soo Pieng's highly stylised figures that began to appear in the latter's work during the 1950s onwards.

${ }^{10}$ The tjili is a figure of a goddess usually featured on the palm leaves that are hung on shrines in Bali.

11 Ancestral figures usually carved on wood and employed by many native communities of Island Southeast Asia.

${ }^{12}$ See Cheong Soo Pieng's and Yeh Chi Wei's series of artworks which featured the Dayak communities.

\section{References}


Ahmed, S. et. al. (Eds.) (2003). Uprootings/Regroundings: Questions of Home and Migration. New York: Berg.

Ang, Ien. (2001). On Not Speaking Chinese: Living between Asia and the West. London: Routledge.

Armstrong, P. B. (2001). Play and Cultural Differences. In Williams, P. (Ed.). Edward Said. pp. 64-78. London: Sage Publications.

Arnheim, R. (1988). The Power of the Centre: A study of composition in the visual arts. Berkeley: University of California Press.

Canclini, N. G. (2000). The State of War and the State of Hybridization. In Gilroy, P., Grossberg, L.\& McRobbie, A.(Eds.). Without Guarantees: In Honour of Stuart Hall, pp. 38-52. London: Verso.

Chen, W. (2006). Convergences: Chen Wen Hsi Centennial Exhibition. Vols. 1-2. Singapore: Singapore Art Museum.

Chia, W. H. (2001). See Cheen Tee: Artist extraordinaire: master draughtsman, printmaker, painter, and cartoonist. Singapore: Raffles Avenue Edition.

Chung, C. S. (2004). The Paintings of Chung Chen Sun (2 ${ }^{\text {nd }}$ Ed.) Kuala Lumpur: Chung Chen Sun Art Museum.

Clifford, James. (1994). Diasporas. Cultural Anthropology. pp. 302-338. doi:10.1525/can. 1994.9.3.02a00040

Coombes, A. (1998). Reinventing the "PostColonial": Hybridity and Constituency in Contemporary Curating. In Preziosi. D. (Ed.). The Art of Art History, pp 486-497. Oxford: Oxford University Press.

Croizier, R. (1993). The Juelanshe (Storm Society) and the fate of Modernism in Republican China. In Clark, J.(Ed.). Modernity in Asian Art. pp. 135-154. Sydney: Wild Peony.

Hall, S.\& Du Gay, P. (Eds.) (1996). Questions of Cultural Identity. London: Sage.

Harris, J. (2001). The New Art History: A Critical Introduction. London: Routledge.

Kalra, V., Kaur, R. \& Hutnyk, J. (2005). Diaspora and Hybridity. London: Sage Publications.

Kang, L. (2011). The voice of the Motherland. In Siew, S. (Ed.). Essays on Art \& Culture. pp. 21-23. Singapore: National Art Gallery.

Kang, L. (2011). Trip to Bali. In Siew, S. (Ed.). Essays on Art \&Culture. pp. 57-62. Singapore: National Art Gallery.

Kao, M. (1988). The Quest for New Art. In Kao, M(Ed.). Twentieth-Century Chinese Painting. pp. 130-160. Hong Kong: Oxford University Press.

Kwok, K. C. (1993). Chen Chong Swee: His Thoughts. In Chen Chong Swee: His Thoughts, His Art. pp. 8-17. Singapore: National Museum.

Kwok, K. C. (1996). Channels \& Confluences: A History of Singapore Art. Singapore: Singapore Art Museum. 
Lim, H. A. (2010). Interview, 20 Jul 2010, Audiotape, Access No. 0003452/7, Collection of Oral History Recording, National Archives, Singapore.

Papastergiadis, N. (2005). Hybridity and Ambivalence. Places and Flows in Contemporary Art and Culture. Theory, Culture and Society, 20: 39-64.doi: 10.1177/0263276405054990

Pieterse, J. N. (2012). Hybridity, So What? : The Anti-Hybridity backlash and the riddles of recognition. Theory, Culture and Society. Sage, 18(219) 219-245. Retrieved 9 January 2012.

Piyadasa, R. (1994, January 1). In search of a tropical paradise. Business Times, p 20.

Radhakrishnan, R. (1993). 'Postcoloniality and the Boundaries of Identity.' Callaloo 16: 750-771, p 753.

Sabapathy, T. K. (1986). The Nanyang Artists. In 'Sources of Modern Art'. Singapore: Ministry of Education.

Seng, Y. J. \& Tng, G. (2010). Bridging Worlds. In Yeo, W. W.(Ed.). Cheong Soo Pieng: Visions of Southeast Asia. pp. 50-133. Singapore: National Art Gallery.

Sullivan, M. (1959). Chinese Art in the $20^{\text {th }}$ Century. London: Faber and Faber.

Yeh, C. W. (1960). Dealing with Modern Art with Patience. Ninth Chung Chen High School Art Exhibition Catalog, 1960. In Yeo, W. W. (Ed.). The Story of Yeh Chi Wei, Vol. 2, pp. 14-21. Singapore: National Art Gallery, 2010.

Yeo, W. W. (Ed.) (2010). Cheong Soo Pieng: Visions of Southeast Asia. Singapore: National Art Gallery. 